OPEN ACCESS

Edited by:

Jouda Mediouni-Ben Jemâa Institut National de la Recherche Agronomique de Tunisie (INRAT),

Tunisia

Reviewed by:

Rania Aydi Ben Abdallah,

Regional Research Centre on Horticulture and Organic Agriculture

(CRRHAB), Tunisia

Anukool Vaishnav,

GLA University, India

${ }^{*}$ Correspondence:

Qian Xu

xuqian@sdau.edu.cn

Qunqing Wang

wangqunqing@163.com

Specialty section: This article was submitted to

Plant Metabolism and Chemodiversity,

a section of the journal

Frontiers in Plant Science

Received: 30 May 2021

Accepted: 30 August 2021 Published: 22 September 2021

Citation:

Ge T, Gao W, Liang C, Han C, Wang Y, Xu $Q$ and Wang $Q$ (2021) 4-Ethylphenol, A Volatile Organic

Compound Produced by

Disease-Resistant Soybean, Is a Potential Botanical Agrochemical Against Oomycetes.

Front. Plant Sci. 12:717258. doi: 10.3389/fpls.2021.717258

\section{4-Ethylphenol, A Volatile Organic Compound Produced by Disease-Resistant Soybean, Is a Potential Botanical Agrochemical Against Oomycetes}

\author{
Ting Ge ${ }^{1,2}$, Wenteng Gao ${ }^{1,2}$, Changhui Liang ${ }^{1,2}$, Chao Han ${ }^{1}$, Yong Wang ${ }^{3}$, Qian $\mathrm{Xu}^{2,4 *}$ and \\ Qunqing Wang ${ }^{1,2 *}$
}

1 Shandong Province Key Laboratory of Agricultural Microbiology, Department of Plant Pathology, College of Plant Protection, Shandong Agricultural University, Tai'an, China, ${ }^{2}$ State Key Laboratory of Crop Biology, Shandong Agricultural University, Tai'an, China, ${ }^{3}$ Shimadzu (China) Co., Ltd., Beijing, China, ${ }^{4}$ College of Agronomy, Shandong Agricultural University, Tai'an, China

Oomycetes, represented by Phytophthora, are seriously harmful to agricultural production, resulting in a decline in grain quality and agricultural products and causing great economic losses. Integrated management of oomycete diseases is becoming more challenging, and plant derivatives represent effective alternatives to synthetic chemicals as novel crop protection solutions. Biologically active secondary metabolites are rapidly synthesized and released by plants in response to biotic stress caused by herbivores or insects, as well as pathogens. In this study, we identified groups of volatile organic compounds (VOCs) from soybean plants inoculated with Phytophthora sojae, the causal agent of soybean root rot. 4-Ethylphenol was present among the identified VOCs and was induced in the incompatible interaction between the plants and the pathogen. 4-Ethylphenol inhibited the growth of $P$. sojae and Phytophthora nicotianae and had toxicity to sporangia formation and zoospore germination by destroying the pathogen cell membrane; it had a good control effect on soybean root rot and tobacco black shank in the safe concentration range. Furthermore, 4-Ethylphenol had a potent antifungal activity against three soil-borne phytopathogenic fungi, Rhizoctonia solani, Fusarium graminearum, and Gaeumannomyces graminis var tritici, and four forma specialis of Fusarium oxysporum, which suggest a potential to be an eco-friendly biological control agent.

Keywords: 4-Ethylphenol, leaf volatile compounds, cell membrane damage, biological control, Phytophthora

\section{INTRODUCTION}

Oomycetes, encompassing Phytophthora, Albugo, Pythium, and a group of downy mildews that cause plant epidemics, have a negative impact on natural and farm ecosystems due to their strong pathogenicity and infectivity (Yutin et al., 2008; Kamoun et al., 2015). Besides the well-known potato late blight caused by Phytophthora infestans, which led to the Irish famine of the 19th 
Century, Phytophthora nicotianae is a pathogen distributed worldwide, and it causes tobacco black shank and is responsible for many foliar and fruit diseases (Fang et al., 2016). Soybean root rot is caused by Phytophthora sojae and is the leading cause of global soybean production losses (Tyler, 2007). Oomycetes are phylogenetically different from fungi, forming an independent group, and are therefore resistant to many broad-spectrum fungicides (Tyler et al., 2006). Some of the fungicides effective against oomycetes, such as metalaxil, have resulted in the emergence of insensitive strains and resurgence events due to their single site of action (Randall et al., 2014). Interdisciplinary studies and consistent resources have been invested in finding new, effective alternatives for the integrated pest management of oomycete diseases (Gessler et al., 2011).

Novel pharmaceuticals against oomycetes should be explored for rational fungicide design, and further focus should be placed on developing alternative botanical agrochemicals to fight different pathogens that attack crops and related products (Drakopoulos et al., 2020; Liang et al., 2021; Wang et al., 2021). Environmentally friendly botanical fungicides are widely welcomed due to their higher efficiency, lower residue, and lower negative impact on the environment (Naz et al., 2018; Tschoeke et al., 2019). Plants are a rich natural source of active antimicrobial substances (Nino et al., 2012; Hu et al., 2018). For example, artemisinin, present in sweet wormwood, a Chinese medicinal plant, is the most effective antimalarial drug available (Tu, 2011).

Natural products have a long history as a source of novel agrochemicals (Yoon et al., 2013). Phytopathologists search for alternative botanical products to replace synthetic fungicides and effectively control plant diseases without significantly affecting crop yields (Bowers and Locke, 2000). For example, poacic acid, which is derived from grass lignocellulosic hydrolysates, inhibits the growth of the Sclerotinia sclerotiorum and Alternaria solani fungi and the oomycete P. sojae (Piotrowski et al., 2015). Pathogen cells treated with poacic acid suffer similar effects to those treated with cell wall-targeting synthetic drugs (Lee et al., 2018). There is considerable evidence for the protective effects of phytochemicals isolated from tissue exudates or volatiles against disease propagation (Drakopoulos et al., 2020; Liao et al., 2021; Wang et al., 2021). For example, grape cane $\varepsilon$-viniferin has antifungal activity against Plasmopara viticola and Botrytis cinerea (Schnee et al., 2013). Secomicromelin, coumarin, isomicromelin, and micromarin B, present in Micromelum falcatum fruits, inhibit the growth of Pythium insidiosum (Suthiwong et al., 2014). Cuminic acid, isolated from cumin seeds (Cuminum cyminum L.), inhibits Phytophthora capsici mycelial growth and zoospore germination (Wang et al., 2016). Gossypol, naturally present in cotton root tissues, has a strong inhibitory activity on Pythium irregulare, Pythium ultimum, and Fusarium oxysporum growth (Mellon et al., 2014).

Leaf volatile organic compounds (VOCs) are rapidly emitted when plants respond to biotic stress caused by herbivores or attacks by necrotrophic fungi (Scala et al., 2013; Matsui and Koeduka, 2016; Tanaka et al., 2018). VOC production is a basic defense mechanism for plants to enhance resistance or tolerance to upcoming stresses and may contribute to direct plant defense responses through their powerful antimicrobial activities (Jerkovic et al., 2012; Krajaejun et al., 2012; Ulloa-Benitez et al., 2016; Ricciardi et al., 2021).

Here, we analyzed soybean leaf volatiles produced in incompatible interaction and compatible interaction with $P$. sojae. A group of VOCs was identified by headspace solidphase microextraction coupled with gas chromatography-mass spectrometry (HS-SPME-GC-MS), which were specifically present in the incompatible interaction. In Petri dish assays, 4Ethylphenol, a volatile phenolic substance, inhibited the mycelial growth, sporangia formation, and zoospore germination of $P$. sojae and P. nicotianae. Additionally, it had potent antifungal activities against three soil-borne phytopathogenic fungi, Rhizoctonia solani, Fusarium graminearum, Gaeumannomyces graminisvar, and four Fusarium oxysporum forma specialis. We found that 4-Ethylphenol triggers mycelia malformation and cytoplasmic electrolyte leakage because of a disrupted or disintegrated plasma membrane. Finally, we analyzed the potential of 4-Ethylphenol as an oomycete biological control agent and confirmed its efficacy in controlling soybean root rot and tobacco black shank diseases in potted plants, and observed a positive effect on plant growth when present in low concentrations.

\section{MATERIALS AND METHODS}

\section{Plant and Phytophthora spp. Cultivation}

Soybean and tobacco plants were grown in a chamber at $25^{\circ} \mathrm{C}$, with a cycle of $16 \mathrm{~h}$ of high light intensity and $8 \mathrm{~h}$ of darkness. P. sojae strain $\mathrm{P} 6497$ and P. nicotianae strain INRA-310 were grown on $10 \% \mathrm{~V} 8$ medium (10\% V8 juice, $0.02 \% \mathrm{CaCO}_{3}$, and $1.5 \%$ agar) in the darkness at $25^{\circ} \mathrm{C}$. Mycelia were cultured in V8 liquid medium. To observe zoosporangia, the mycelia were washed with sterile water five times and cultured in the darkness at $25^{\circ} \mathrm{C}$ for $6 \mathrm{~h}$. When zoosporangia formed, zoospores were released after washing with sterile water at $10^{\circ} \mathrm{C}$ three times. Finally, the concentration of the zoospore suspension was adjusted to $10^{5} \mathrm{CFU} / \mathrm{mL}$.

\section{Gas Chromatography-Mass Spectrometry Analysis}

Soybean leaves (Williams and Williams-82 cultivars) inoculated with $P$. sojae were placed in a $20 \mathrm{~mL}$ headspace bottle, and the VOCs were analyzed with gas chromatographymass spectrometry (GC-MS). An AOC-6000 Multifunctional Autosampler was used for solid-phase microextraction injection, and GCMS-TQ8040 NX was used for detection following the standard SPME parameters (SPME fiber: FIB-C-WR95/10. The following parameters were used: aging temperature, $240^{\circ} \mathrm{C}$; aging time (before extraction), $30 \mathrm{~min}$; equilibration temperature, $40^{\circ} \mathrm{C}$; equilibration time, $5 \mathrm{~min}$; extraction time, $30 \mathrm{~min}$; injection port temperature, $250^{\circ} \mathrm{C}$; desorption time, $2 \mathrm{~min}$; and aging time (after extraction), $5 \mathrm{~min}$. The GCMS/MS parameters used were: column, inert cap pure-wax, $30 \mathrm{~m} \times 0.25 \mathrm{~mm} \times 0.25 \mathrm{~m}$; oven program, $50^{\circ} \mathrm{C}(5 \mathrm{~min})$, 
$10^{\circ} \mathrm{C} / \mathrm{min} \_250^{\circ} \mathrm{C}(10 \mathrm{~min})$; carrier gas pressure, $83.5 \mathrm{kPa}$; injection mode, split; split ratio, 5:1; ion-source temperature, $200^{\circ} \mathrm{C}$; interface temperature, $250^{\circ} \mathrm{C}$; detector voltage, tuning voltage $+0.3 \mathrm{kV}$; and acquisition mode, MRM.

\section{Effect of 4-Ethylphenol on the Radial Growth of Phytophthora spp. Hyphae}

Hyphal plugs of $P$. sojae and $P$. nicotianae were cultured in $10 \%$ V8 agra medium containing different concentrations of 4Ethylphenol, or the same volume of sterile water as a control. The medium was incubated in the darkness at $25^{\circ} \mathrm{C}$ for 5 days; then, the colony diameter was measured, and the mycelium status was observed under the microscope. Each treatment was repeated three times.

\section{Effects of 4-Ethylphenol on Phytophthora spp. Zoosporangium Formation and Zoospore Release}

Washed mycelia were placed in different concentrations of 4Ethylphenol. After incubation at $25^{\circ} \mathrm{C}$ for $6 \mathrm{~h}$, the number of zoosporangia was observed and recorded under the microscope using Mallassez cell counting. 4-Ethylphenol was added to the sporangium-forming dishes, and after $2 \mathrm{~h}$, the number of zoospores was measured under the microscope using Mallassez cell counting. Each treatment was repeated three times.

\section{Effects of 4-Ethylphenol on Phytophthora spp. Zoospore Germination}

The $0.1 \mathrm{~mL}$ zoospore suspension was evenly spread on V8 medium containing four different concentrations of 4Ethylphenol. After incubation at $25^{\circ} \mathrm{C}$ for 4 days, the minimum concentration with no colony formation was determined by naked eye observation. Each treatment was repeated three times.

\section{Effect of 4-Ethylphenol on Phytophthora sojae Virulence}

Soybeans were planted in the dark for 7 days, and etiolated seedlings were immersed in 4-Ethylphenol solution for $1 \mathrm{~h}$ and then placed in zoospore suspension for infection. After 4 or $6 \mathrm{~h}$ of infection, the hypocotyls were collected and stained with a lactophenol-trypan blue dye solution. After $2 \mathrm{~h}$ of staining, samples were destained with chloral hydrate until they were translucent. The discolored epidermis was then removed with forceps, prepared, and observed under the microscope. Each treatment was repeated three times.

\section{Damage of the Phytophthora spp. Cell Membrane by 4-Ethylphenol}

Mycelia were cultured in V8 liquid medium for 3 days. Washed mycelia were placed in PBS buffer ( $\mathrm{pH}$ 7.0) containing 4Ethylphenol; DNA and protein concentrations were measured and recorded every $2 \mathrm{~h}$. Each treatment was repeated three times.

\section{Safety of 4-Ethylphenol on Soybean and Tobacco Plants}

Different concentrations of 4-Ethylphenol (0-25 mg a.i./plant) were mixed with soil. The growth and development of soybean and tobacco plants were recorded at 7 and 14 days after treatment, respectively. Each treatment was repeated three times.

\section{Efficacy of 4-Ethylphenol as a Soil Fumigant}

Different concentrations of 4-Ethylphenol were mixed with soil and then sealed in plastic film for 15 days. After being air-cured for 2 days, soybean and tobacco were planted in the soil, and their growth and development were observed after 9 days. Each treatment was repeated three times.

\section{Statistical Analysis}

Statistical analysis was performed using Statistical Product and Service Solutions (SPSS) 19.0. The difference among treatments was determined based on one-way analysis of variance (ANOVA), and means were subjected to Duncan's multiple range test with significance set at $P<0.05$.

\section{RESULTS}

\section{Detection of the VOC 4-Ethylphenol in Soybean Leaves}

We investigated the VOCs produced in the leaves of susceptible soybean plants (Williams), lacking resistance genes to $P$. sojae (Rps), and resistant soybean plants (Williams82), containing the Rps1k resistance gene, by GC--MS. The 4-Ethylphenol content in Williams82 was significantly higher than that in Williams leaves (Supplementary Figure 1), suggesting that 4-Ethylphenol is involved in the defense response of soybean to $P$. sojae.

\section{Effect of 4-Ethylphenol on the Mycelium Growth of Phytophthora spp.}

The radial diameter of $P$. sojae and $P$. nicotianae colonies grown on V8 medium supplemented with different concentrations of 4-Ethylphenol was determined through naked eye observation; the toxicity of 4-Ethylphenol to Phytophthora spp. was observed and calculated (Figure 1A). The average diameter of P. nicotianae colonies cultured for 5 days on V8 medium containing $0.4 \mathrm{mmol}$ (57.66 mg/L) of 4-Ethylphenol was $20.52 \mathrm{~mm}$, and the inhibition rate was $57.73 \%$ (Figure 1B). Additionally, the average diameter of $P$. sojae colonies cultured for 5 days on V8 medium containing $0.6 \mathrm{mmol}(86.48 \mathrm{mg} / \mathrm{L})$ of 4 -Ethylphenol was $20.50 \mathrm{~mm}$, and the antifungal rate was $54.14 \%$. Medium containing $1 \mathrm{mmol}$ $(144.14 \mathrm{mg} / \mathrm{L})$ of 4 -Ethylphenol completely inhibited the growth of both oomycete species (Figure 1C).

\section{Effect of 4-Ethylphenol on the Morphology and Cell Membrane of Phytophthora spp. Hyphae}

Phytophthora spp. hyphae grew naturally in V8 medium, without increased terminal branching; the mycelium growing points 


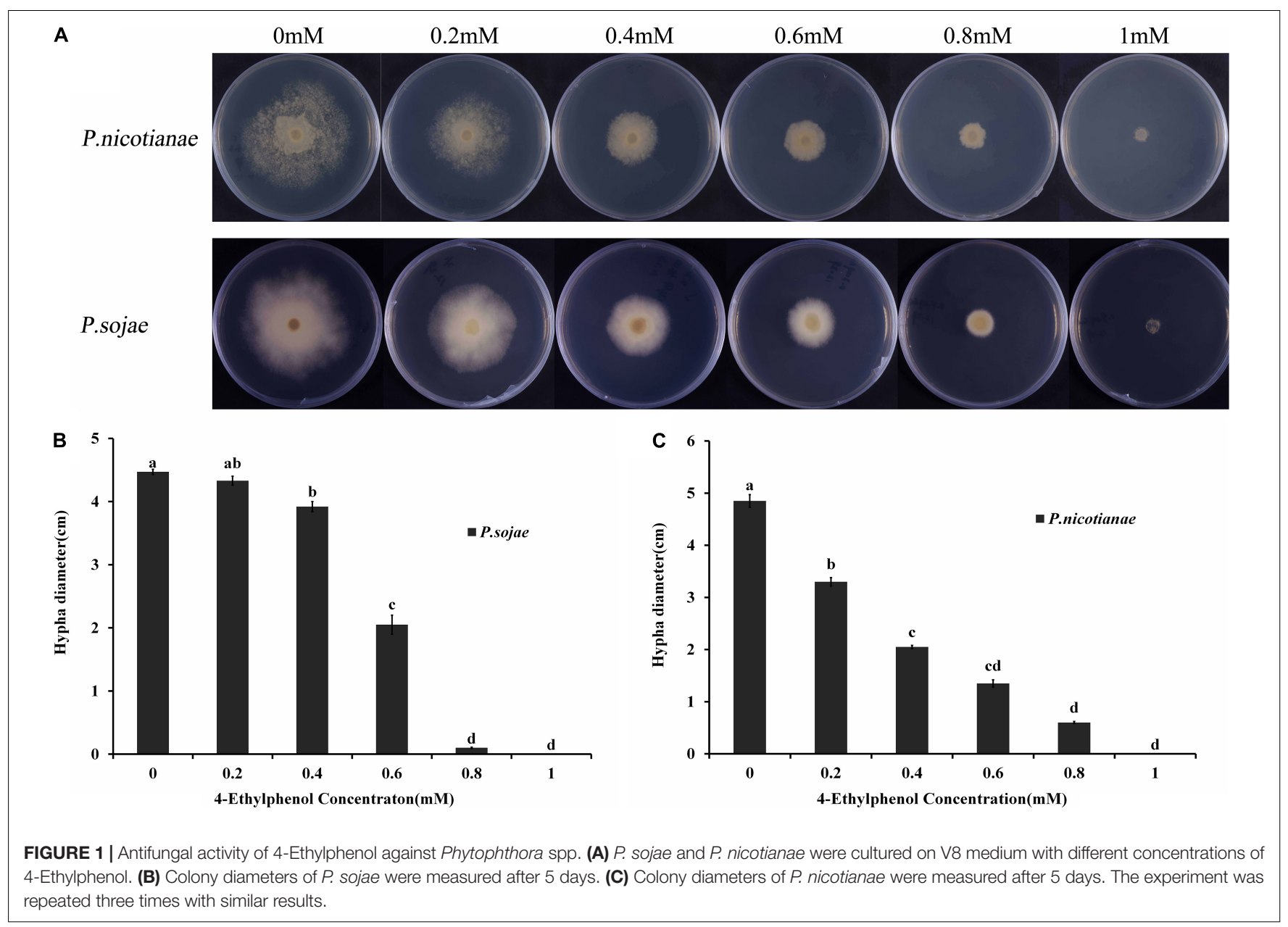

were uniform, and the branches formed far from the top. After treatment with $0.4 \mathrm{mmol}$ of 4 -Ethylphenol, the growth of $P$. sojae and $P$. nicotianae hyphae was inhibited in the V8 liquid medium. The morphology of the mycelia changed in the presence of 4Ethylphenol, and the branches at the end increased significantly and became disordered (Figure 2A). The results showed that 4-Ethylphenol inhibited growth by changing the morphology of Phytophthora spp. hyphae. To analyze the mechanisms of antimicrobial activity against $P$. sojae and $P$. nicotianae, we treated mycelia with 4-Ethylphenol and investigated the presence of leakage of cellular material. By monitoring the total DNA and protein concentrations in the media every $2 \mathrm{~h}$, we observed that the contents increased significantly with time, and the intensity of leakage increased with 4-Ethylphenol concentration (Figures 2B,C). The leakage of cellular contents was likely due to the destruction of the cell membrane by 4-Ethylphenol.

\section{Inhibition Effect of 4-Ethylphenol on the Formation of Sporangium and Zoospores of Phytophthora spp.}

To study the effect of 4-Ethylphenol on Phytophthora spp. zoosporangia formation, we determined the number of zoosporangia and calculated the inhibition degree after treatments with different concentrations of the VOC. The formation of $P$. sojae zoosporangia was significantly reduced by $0.2 \mathrm{mmol}$ of 4 -Ethylphenol, while no zoosporangium was formed with $1 \mathrm{mmol}$. For $P$. nicotianae, $0.4 \mathrm{mmol}$ of 4 -Ethylphenol significantly reduced zoosporangium formation, whereas $0.8 \mathrm{mmol}$ of 4-Ethylphenol completely inhibited it (Figure 3A).

Additionally, zoospore release from both $P$. sojae and $P$. nicotianae sporangia was significantly reduced with $0.4 \mathrm{mmol}$ of 4-Ethylphenol, and completely inhibited with $0.8 \mathrm{mmol}$ of 4-Ethylphenol (Figure 3B).

\section{Effect of 4-Ethylphenol on Phytophthora spp. Zoospore Germination}

To analyze the effect of 4-Ethylphenol on Phytophthora spp. zoospore germination, we spread a zoospore suspension evenly on $1 \% \mathrm{~V} 8$ medium containing different concentrations of the VOC. Compared with control, $0.4 \mathrm{mmol}$ of 4 -Ethylphenol significantly inhibited the germination of $P$. sojae zoospores; only a few zoospores could germinate and form separate colonies. At $0.8 \mathrm{mmol}$ of 4 -Ethylphenol, the germination of zoospores was completely inhibited. For $P$. nicotianae, $0.6 \mathrm{mmol}$ of 4-Ethylphenol significantly inhibited zoospore germination, and $1 \mathrm{mmol}$ completely inhibited it (Supplementary Table 1). 
A

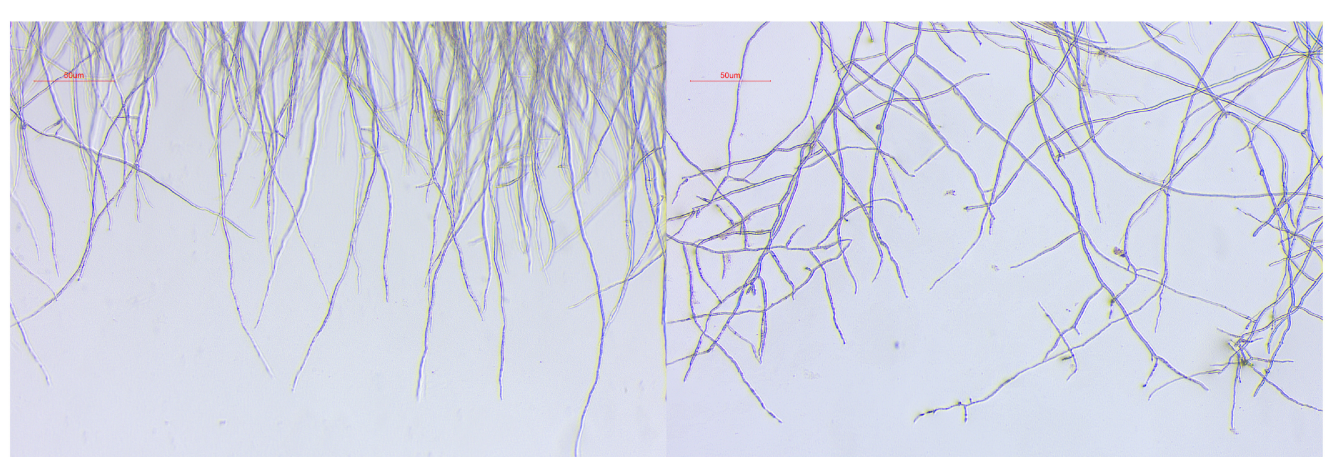

P. sojae

$\mathrm{H}_{2} \mathrm{O}$

4-EP

$\mathrm{H}_{2} \mathrm{O}$
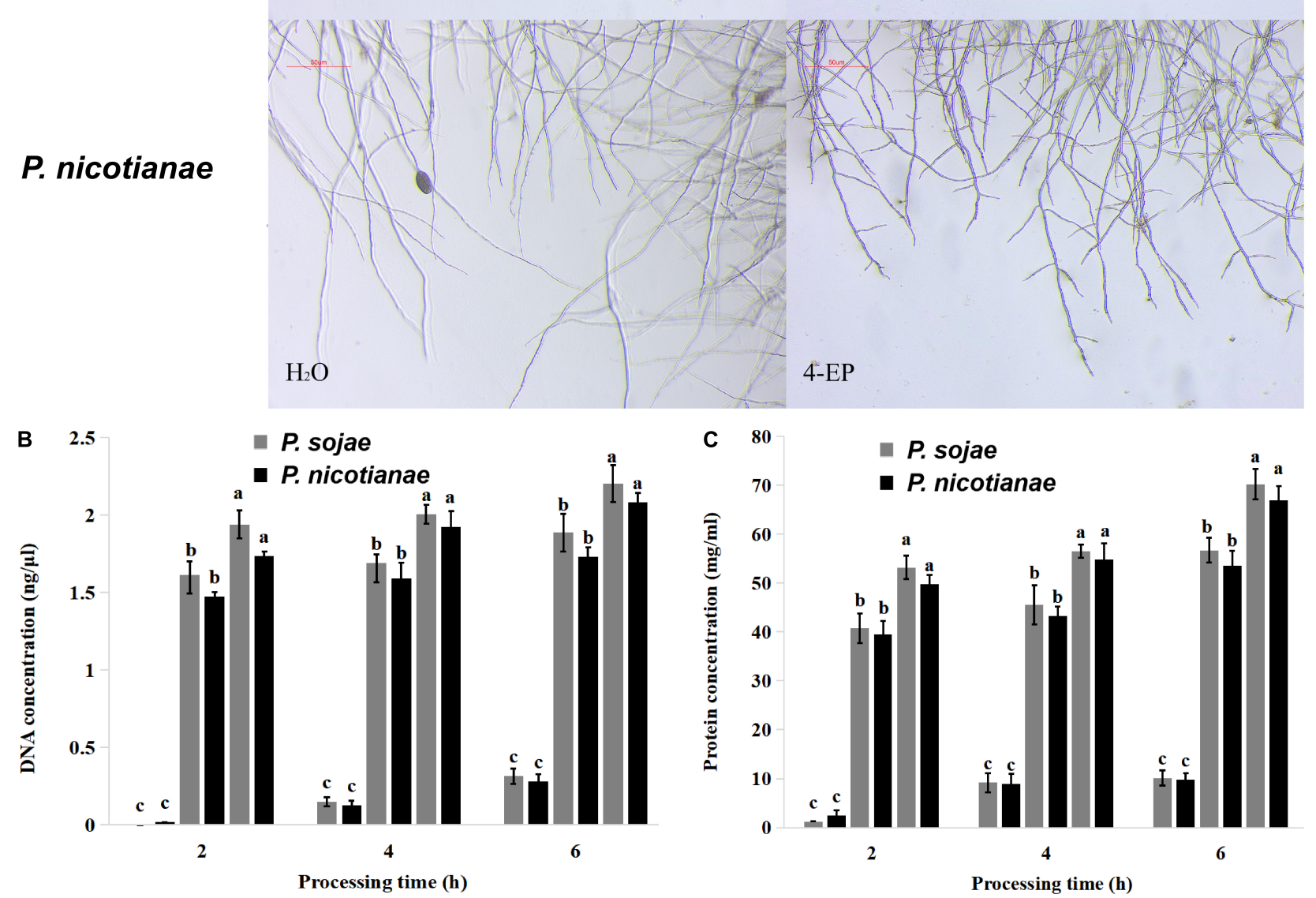

C $80 \square$ P. sojae

- P. nicotianae

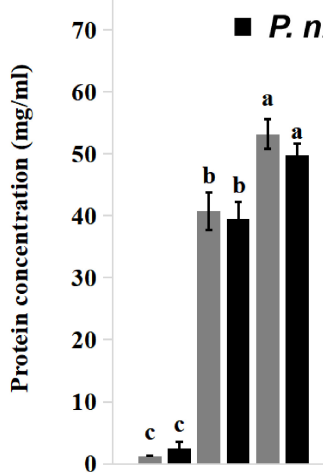

2

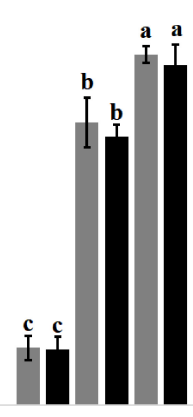

4

Processing time (h)

FIGURE 2 | Effect of 4-Ethylphenol on Phytophthora spp. morphology and DNA and protein leakage. (A) Effect of 4-Ethylphenol on the morphology of $P$. sojae and $P$. nicotianae treated with 4-Ethylphenol for 2 h; $\mathbf{( B )}$ effect of 4-Ethylphenol on DNA leakage of $P$. sojae and $P$. nicotianae; (C) effect of 4 -Ethylphenol on protein leakage of $P$. sojae and $P$. nicotianae.

\section{Effect of 4-Ethylphenol on Phytophthora sojae Zoospore Invasion}

Phytophthora sojae zoospores treated with the control could attach to the epidermis of soybean hypocotyls, and some of them could form germ tubes at $4 \mathrm{~h}$ post-inoculation (hpi) (Figure 4A). At $6 \mathrm{hpi}$, more zoospores were attached to the epidermis, and the majority had germinated hyphae for infection (Figure 4B). Treatment with 4-Ethylphenol significantly reduced the zoospore adhesion ability, and only a few attached to the surface of soybean hypocotyls at 4 hpi (Figure 4C). At 6 hpi, the zoospore attachment and germination decreased significantly compared with the control (Figure 4D), indicating that 4-Ethylphenol could effectively inhibit zoospores from infecting soybean.

\section{Effect of 4-Ethylphenol on Germination and Growth of Soybean and Tobacco Plants}

To investigate the safety of 4-Ethylphenol for host plants, we planted soybean and tobacco seedlings in soil mixed with different concentrations of 4-Ethylphenol, and seedling heights 

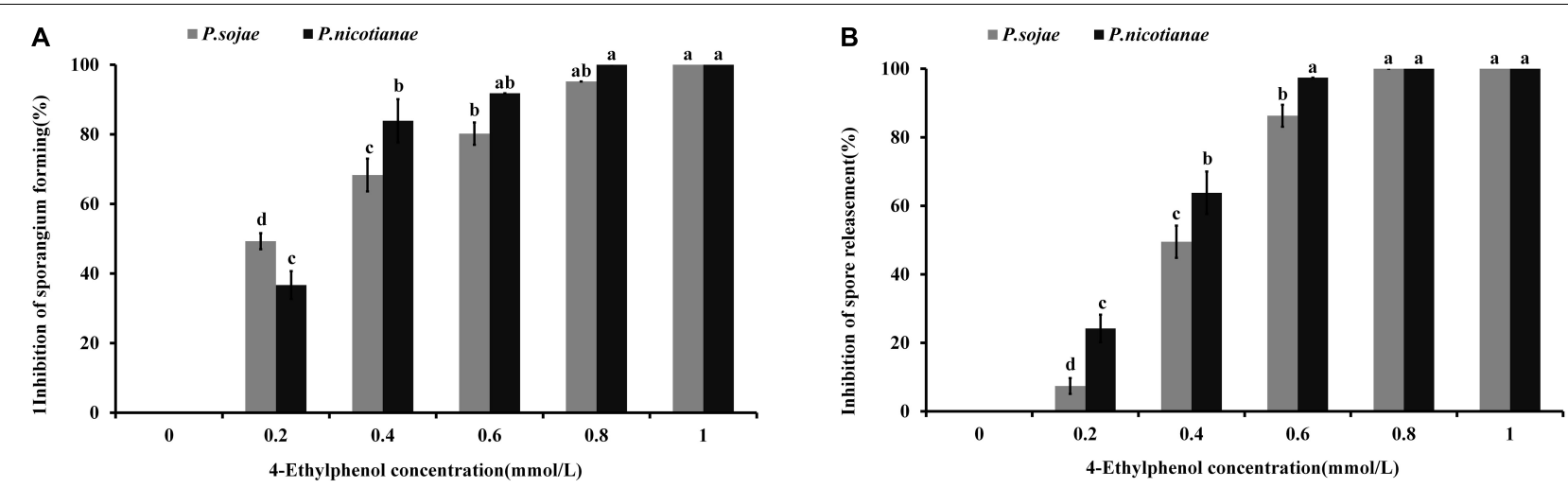

FIGURE 3 | Effect of 4-Ethylphenol on zoosporangium formation and zoospore release. (A) Inhibition rate of 4-Ethylphenol on $P$. sojae and $P$. nicotianae zoosporangium formation; (B) inhibition rate of 4-Ethylphenol on $P$. sojae and $P$. nicotianae zoospore release. The experiment was repeated three times with similar results.
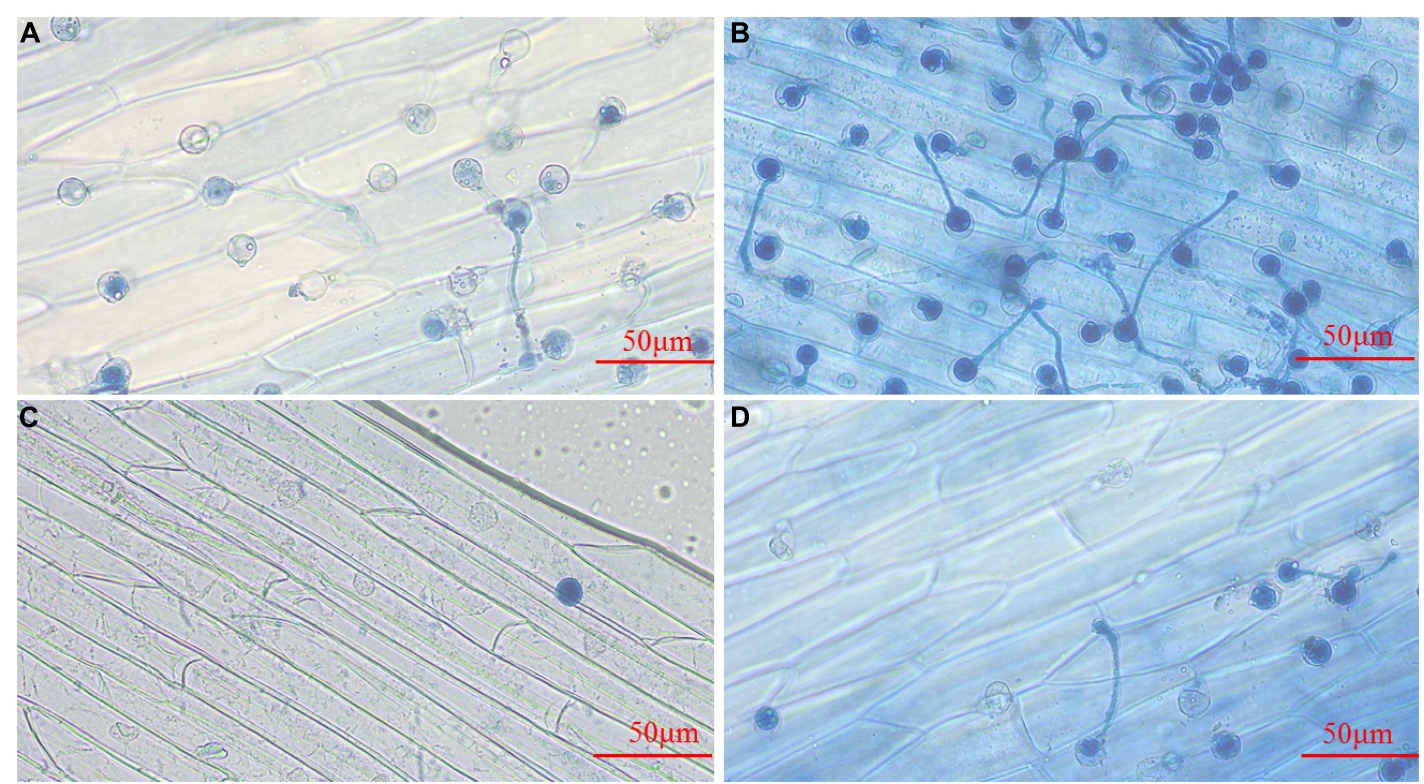

FIGURE 4 | Effect of 4-Ethylphenol on P. sojae zoospore invasion. Zoospore invasion after (A) 4 h of the control treatment (water), (B) $6 \mathrm{~h}$ of the control treatment (water), (C) 4 h of the 4-Ethylphenol treatment, (D) 6 h of the 4-Ethylphenol treatment. The control-treated $P$. sojae zoospores attached to the hypocotyls of yellow-yellow seedlings and grew many hyphae for infection, whereas the $P$. sojae treated with 4-Ethylphenol significantly reduced the adhesion and infection ability. The experiment was repeated three times, and similar results were obtained.

were measured 7 and 14 days after the treatment (Figure 5). The results showed that the germination rate of soybean plants under all tested concentrations reached $100 \%$, indicating that 4-Ethylphenol did not affect soybean seed germination. The average height of soybean plants increased compared with the control with treatments at low concentrations, indicating that 4-Ethylphenol promoted the growth of soybean plants. The maximum concentration tested, $25 \mathrm{mg}$ a.i./plant, had no obvious inhibitory effects on seedling height, indicating that 4-Ethylphenol did not affect the normal soybean growth (Figure 5A and Supplementary Figure 2A). Regarding tobacco plants, the average height of plants with 4-Ethylphenol was not significantly different from that of the control group after 7 and
14 days (Figure 5B and Supplementary Figure 2A). Tobacco seedlings treated with different concentrations grew normally and somewhat consistently.

\section{Efficacy of 4-Ethylphenol Against Soybean Root Rot and Tobacco Black Shank Diseases}

Based on the results from the concentration gradient safety test, we planted soybean and tobacco on soil mixed with 4-Ethylphenol and mycelia to observe the control effect on soybean root rot and tobacco black shank. The results showed that control-treated soybean plants (no pathogen) grew 

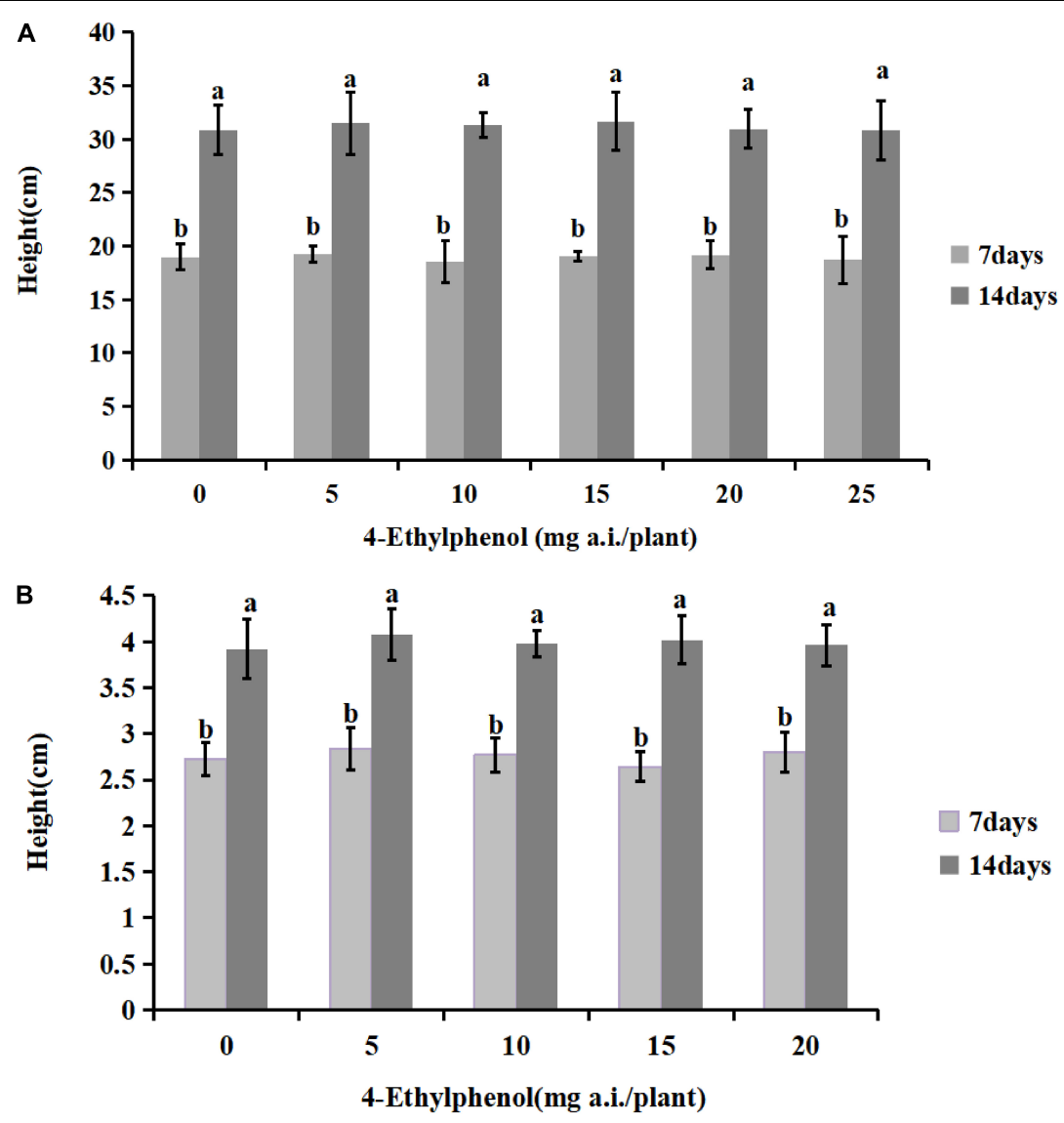

FIGURE 5 | Effects of 4-Ethylphenol on soybean $\mathbf{( A )}$ and tobacco $\mathbf{( B )}$ height. Data are the mean \pm S.E. from three replicates per treatment.

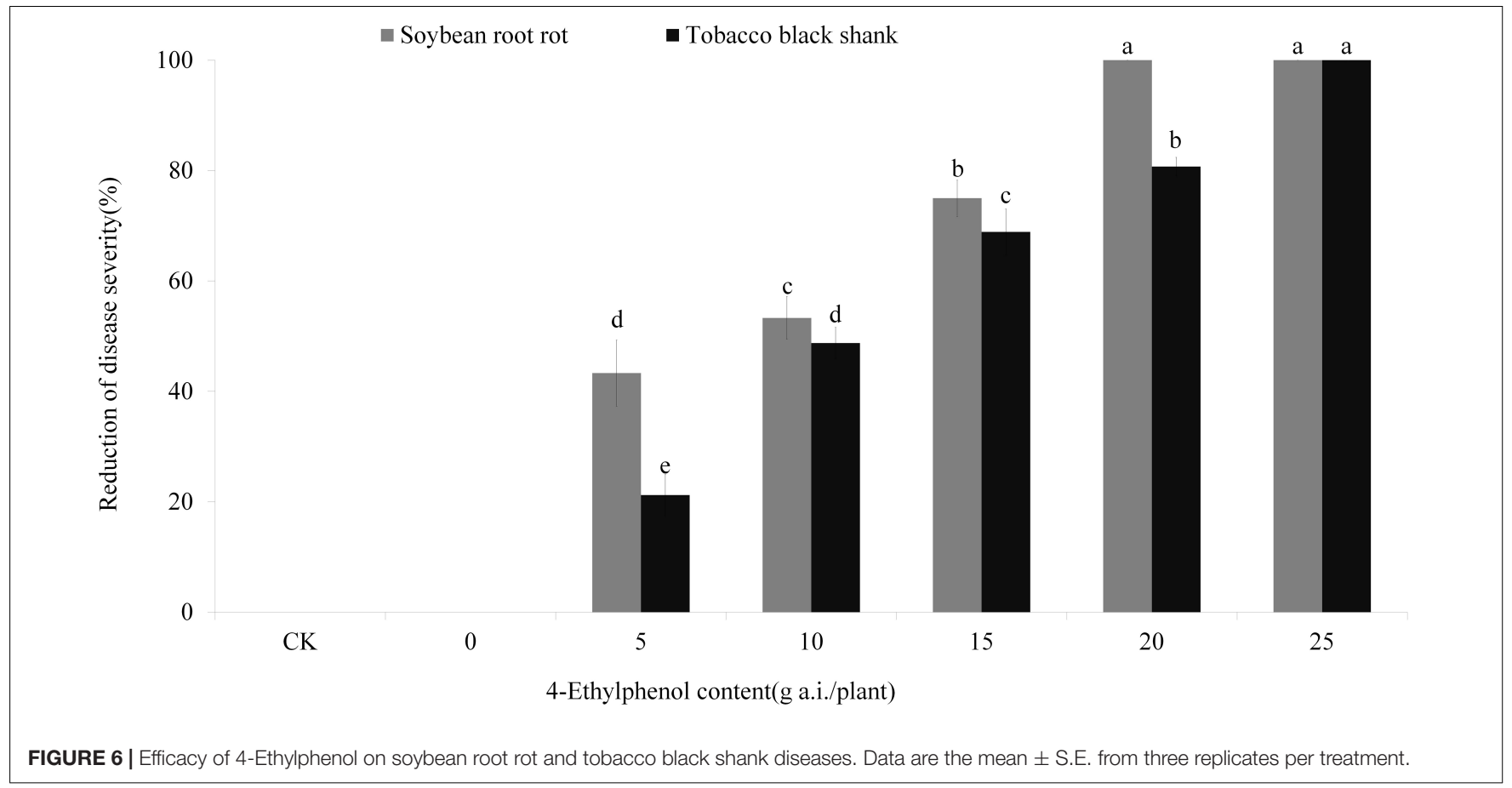


normally, whereas those treated with $P$. sojae-containing soil had serious disease symptoms (Figure 6 and Supplementary Figure 3B). With the increase in 4-Ethylphenol concentration, the disease index decreased gradually, and the relative control effect improved. When $20 \mathrm{mg}$ a.i./plant of 4-Ethylphenol was mixed with soil, the control effect reached $100 \%$, and soybean plants were healthy (Figure 6 and Supplementary Figure 3A). Furthermore, tobacco plants grown without the pathogen grew normally, whereas adding $P$. nicotianae to the soil prompt quick plant death. Application of 4-Ethylphenol decreased the disease index gradually in a dose-dependent response and the tobacco plants were mostly healthy. When $25 \mathrm{mg}$ of 4-Ethylphenol was applied per pot, all tobacco plants grew normally, and the control effect reached 100\% (Figure 6 and Supplementary Figure 3B).

\section{DISCUSSION}

Oomycetes are fungus-like organisms that include a group of notorious phytopathogens, namely Phytophthora, Albugo, Pythium, and downy mildews (Kamoun et al., 2015). Although oomycetes resemble filamentous fungi (Jiang and Tyler, 2012), they are phylogenetically related to diatoms and brown algae in the stramenopiles (Tyler et al., 2006; Haas et al., 2009; Thines and Kamoun, 2010; Tan et al., 2020). The well-documented Irish famine forced humans to investigate the causes of the potato late blight and discover the responsible microbial pathogen, $P$. infestans (Haas et al., 2009). Since the 1870s, breeding efforts for late blight resistance have failed to provide a durable, resistant cultivar (DeArce, 2008). To control late blight, farmers rely largely on fungicides with unknown modes of action (Rekanovic et al., 2012; Ferreira et al., 2014; Randall et al., 2014; Childers et al., 2015; Miao et al., 2016; Chen et al., 2018). Many fungicides are ineffective against oomycetes because of their phylogenetic differences (Siegenthaler and Hansen, 2021). Although some fungicides have had some effect on oomycetes, widespread use quickly caused fully insensitive races to emerge (Randall et al., 2014; Childers et al., 2015; Matson et al., 2015; Pang et al., 2016). Currently, $P$. infestans remains a major constraint to the global production of potato and tomato and is thus a constant threat to food security (Haverkort et al., 2008; Fisher et al., 2012). In addition to late blight, Phytophthora spp. soybean root rot and tobacco black shank are diseases that are distributed worldwide, which lack effective control methods (Dorrance et al., 2003; Cui et al., 2010; Ji et al., 2014; Li et al., 2017). Copper-based fungicides are effective in crop protection against oomycetes, but they are facing restrictions because of copper accumulation in the soil (Mackie et al., 2013; Wightwick et al., 2013; Thuerig et al., 2018). New sources of fungicides have to keep pace with the evolution of resistant strains and emerging pathogens (Alexander and Perfect, 1997; Jian et al., 2015).

Due to the increasingly stringent regulatory requirements, crop protection approaches will have to ensure environmental conservation and sustainability (Hao et al., 2019; Kapsi et al., 2019). The use of natural products as an alternative to synthetic chemicals in the fight against different phytopathogens remains a constant need (Thuerig et al., 2018; Lorsbach et al., 2019). The primary and secondary metabolites produced by plants are important sources for developing novel environmental-friendly agrochemicals (Dayan et al., 2009). VOCs synthesized and emitted in response to pathogen infection are particularly relevant and usually have functional benefits in multiple aspects of plant defense (Ricciardi et al., 2021; Xu et al., 2021).

In this study, we analyzed the VOCs emitted when soybean plants responded to $P$. sojae. We used an odor analyzer combined with a Triple Quadrupole quality selection detector GCMSTQ8040NX (Simadzu Company, Kyoto, Japan) and AOC-6000 multifunctional automatic sampler to establish an analysis method for VOCs induced in plant leaves. Regarding the software, the Odor Analyzer provides a complete method package and database, which was first released and used to analyze plant VOCs. One hundred and fifty components were determined with this semi-quantitative method, which is easy to operate, rapid to provide and analyze data, and suitable for the rapid screening of plant odors in culture.

Among the 150 components identified, a potent antifungal compound, 4-Ethylphenol, requires further exploration as a source or template for novel crop protection chemistry. There have been a few reports demonstrating the antimicrobial potential of 4-Ethylphenol (Xing et al., 2018). In this study, 4-Ethylphenol had a good inhibitory effect on $P$. sojae and $P$. nicotianae. Zoospore germination and mycelium growth are important for disease epidemics (Tyler et al., 1996). Our results showed that $1 \mathrm{mM}$ (144.15 mg/L) 4-Ethylphenol completely inhibited Phytophthora spp. sporangium formation and mycelium growth. This inhibition is comparable to that of the plant-derived antifungal agent poacic acid when applied with an IC50 of 1,000 mg/L against $P$. sojae (Piotrowski et al., 2015). 4-Ethylphenol has a potent antifungal activity against three soil-borne phytopathogenic fungi, Rhizoctonia solani, Fusarium graminearum, and Gaeumannomyces graminis var tritici, and four Fusarium oxysporum forma specialis. Usually, these fungi are associated with Phytophthora spp. in the soil and cause compound infection complications, which aggravate the occurrence of plant root rot (Pemberton et al., 1998; Wen et al., 2017; Brown et al., 2021). The potent antifungal activity of 4-Ethylphenol could block the spread of these pathogens, and may play a key role in inhibiting soil-borne disease epidemics. This study provides the first report of the activity of 4Ethylphenol against a series of Phytophthora spp. and fungi pathogens, demonstrates its potential as a universal broadspectrum fungicide for soils, and justifies efforts to investigate its mechanism of action in detail.

To understand the mechanisms behind the antimicrobial action of 4-Ethylphenol, we examined the morphology of Phytophthora spp. mycelia treated with the VOC. Mycelium morphology could be changed after treatments with plant essential oils (Huang et al., 2019). Microscopic observation showed that $P$. sojae and $P$. nicotianae mycelia morphology was also changed after 4-Ethylphenol treatment. The leakage of intracellular materials, such as DNA and proteins, was significantly higher in treated mycelia than in the control, 
confirming that 4-Ethylphenol damaged the cell structure and thus affected the normal mycelial growth.

Because it is a potential antifungal agent, plant security studies for 4-Ethylphenol application are necessary. The application of 4-Ethylphenol in a certain concentration range (0-25 mg a.i./plant) did not inhibit or harm normal soybean and tobacco growth. At the lower but effective concentration range (5-15 $\mathrm{mg}$ a.i./plant), it even slightly promoted soybean and tobacco growth.

We further verified that 4-Ethylphenol is effective in controlling soybean root rot and tobacco black shank in pot experiments where, to mimic the field application, 4-Ethylphenol was mixed with soil. The results showed that 4-Ethylphenol could effectively inhibit both the soil-borne pathogens without affecting the normal plant growth. Future work should explore more effective application methods and lay a foundation for creating 4-Ethylphenol field application directives.

Botanical fungicides are derived from natural products and are less likely to develop drug resistance than chemical fungicides (Shuping and Eloff, 2017). None of the natural and eco-friendly chemical alternatives currently registered and available have the full spectrum of activity and versatility of methyl bromide as pre-plant soil fumigants (Duniway, 2002; Driver et al., 2016). Based on the results described here, 4-Ethylphenol is a potent antimicrobial that regulates plant growth and has the potential to substitute traditional antifungal agents.

\section{DATA AVAILABILITY STATEMENT}

The original contributions presented in the study are included in the article/Supplementary Material, further inquiries can be directed to the corresponding author/s.

\section{REFERENCES}

Alexander, B. D., and Perfect, J. R. (1997). Antifungal resistance trends towards the year 2000. Implications for therapy and new approaches. Drugs 54, 657-678. doi: 10.2165/00003495-199754050-00002

Bowers, J. H., and Locke, J. C. (2000). Effect of Botanical Extracts on the Population Density of Fusarium oxysporum in Soil and Control of Fusarium Wilt in the Greenhouse. Plant Dis. 84, 300-305. doi: 10.1094/PDIS.2000.84. 3.300

Brown, M., Jayaweera, D., Hunt, A., Woodhall, J. W., and Ray, R. V. (2021). Yield losses and control by sedaxane and fludioxonil of soil-borne Rhizoctonia, Microdochium and Fusarium species in winter wheat. Plant Dis. [Epub Online ahead of print]. doi: 10.1094/PDIS-11-20-2401-RE

Chen, F., Zhou, Q., Qin, C., Li, Y., and Zhan, J. (2018). Low evolutionary risk of iprovalicarb resistance in Phytophthora infestans. Pestic. Biochem. Physiol. 152, 76-83. doi: 10.1016/j.pestbp.2018.09.003

Childers, R., Danies, G., Myers, K., Fei, Z., Small, I. M., and Fry, W. E. (2015). Acquired Resistance to Mefenoxam in Sensitive Isolates of Phytophthora infestans. Phytopathology 105, 342-349. doi: 10.1094/PHYTO-05-14-0148-R

Cui, L., Yin, W., Tang, Q., Dong, S., Zheng, X., Zhang, Z., et al. (2010). Distribution, Pathotypes, and Metalaxyl Sensitivity of Phytophthora sojae from Heilongjiang and Fujian Provinces in China. Plant Dis. 94, 881-884. doi: 10.1094/PDIS-947-0881

Dayan, F. E., Cantrell, C. L., and Duke, S. O. (2009). Natural products in crop protection. Bioorg. Med. Chem. 17, 4022-4034. doi: 10.1016/j.bmc.2009.01.046

\section{AUTHOR CONTRIBUTIONS}

QW and QX designed the experiments. TG, CL, and WG performed the experiments and analyzed the data. YW performed the GC-MS experiments and analyzed the data. TG and QW wrote the manuscript. QX and $\mathrm{CH}$ participated in manuscript revision or experiments. QW revised the manuscript and provided the funding for this research. All authors contributed to the article and approved the submitted version.

\section{FUNDING}

This work was supported by grants from the Key R\&D projects in Shandong Province (2019GNC106060), the Major Basic Research Program of Shandong Natural Science Foundation 2019JZZY020608, the National Key Research and Development Project of China (2016YFD0100602), and the National Natural Science Foundation of China (31972249 and 31671985).

\section{ACKNOWLEDGMENTS}

We would like to thank the Phytohormone analysis Platform, Agronomy College of SDAU, for providing technical support and suggestions for this research work.

\section{SUPPLEMENTARY MATERIAL}

The Supplementary Material for this article can be found online at: https://www.frontiersin.org/articles/10.3389/fpls.2021. 717258/full\#supplementary-material

DeArce, M. (2008). Correspondence of Charles Darwin on James Torbitt's project to breed blight-resistance potatoes. Arch. Nat. Hist. 35, 208-222. doi: 10.3366/ e0260954108000351

Dorrance, A. E., McClure, S. A., and St Martin, S. K. (2003). Effect of Partial Resistance on Phytophthora Stem Rot Incidence and Yield of Soybean in Ohio. Plant Dis. 87, 308-312. doi: 10.1094/PDIS.2003.87.3.308

Drakopoulos, D., Meca, G., Torrijos, R., Marty, A., Kagi, A., Jenny, E., et al. (2020). Control of Fusarium graminearum in Wheat With Mustard-Based Botanicals: from in vitro to in planta. Front. Microbiol. 11:1595. doi: 10.3389/fmicb.2020. 01595

Driver, J. H., Price, P. S., Van Wesenbeeck, I., Ross, J. H., Gehen, S., Holden, L. R., et al. (2016). Evaluation of potential human health effects associated with the agricultural uses of 1,3-D: spatial and temporal stochastic risk analysis. Sci. Total Environ. 571, 410-415. doi: 10.1016/j.scitotenv.2016.06.172

Duniway, J. M. (2002). Status of chemical alternatives to methyl bromide for preplant fumigation of soil. Phytopathology 92, 1337-1343. doi: 10.1094/PHYTO. 2002.92.12.1337

Fang, Y., Zhang, L., Jiao, Y., Liao, J., Luo, L., Ji, S., et al. (2016). Tobacco Rotated with Rapeseed for Soil-Borne Phytophthora Pathogen Biocontrol: mediated by Rapeseed Root Exudates. Front. Microbiol. 7:894. doi: 10.3389/fmicb.2016. 00894

Ferreira, L. C., Scavroni, J., da Silva, J. R., Cataneo, A. C., Martins, D., and Boaro, C. S. (2014). Copper oxychloride fungicide and its effect on growth and oxidative stress of potato plants. Pestic. Biochem. Physiol. 112, 63-69. doi: 10.1016/j.pestbp.2014.04.010 
Fisher, M. C., Henk, D. A., Briggs, C. J., Brownstein, J. S., Madoff, L. C., McCraw, S. L., et al. (2012). Emerging fungal threats to animal, plant and ecosystem health. Nature 484, 186-194. doi: 10.1038/nature10947

Gessler, C., Pertot, I., and Perazzolli, M. (2011). Plasmopara viticola: a review of knowledge on downy mildew of grapevine and effective disease management. Phytopathol. Mediterr. 50, 3-44.

Haas, B. J., Kamoun, S., Zody, M. C., Jiang, R. H., Handsaker, R. E., Cano, L. M., et al. (2009). Genome sequence and analysis of the Irish potato famine pathogen Phytophthora infestans. Nature 461, 393-398. doi: 10.1038/nature08358

Hao, Y., Li, Y., Han, X., Wang, T., Yang, R., Wang, P., et al. (2019). Air monitoring of polychlorinated biphenyls, polybrominated diphenyl ethers and organochlorine pesticides in West Antarctica during 2011-2017: concentrations, temporal trends and potential sources. Environ. Pollut. 249, 381-389. doi: 10.1016/j.envpol.2019.03.039

Haverkort, A. J., Boonekamp, P. M., Hutten, R., Jacobsen, E., Lotz, L., Kessel, G., et al. (2008). Societal costs of late blight in potato and prospects of durable resistance through cisgenic modification. Potato Res. 51, 47-57.

Hu, Z., Wang, Z., Liu, Y., and Wang, Q. (2018). Leveraging botanical resources for crop protection: the isolation, bioactivity and structure-activity relationships of lycoris alkaloids. Pest Manag. Sci. 74, 2783-2792. doi: 10.1002/ps.5065

Huang, F., Kong, J., Ju, J., Zhang, Y., Guo, Y., Cheng, Y., et al. (2019). Membrane damage mechanism contributes to inhibition of trans-cinnamaldehyde on Penicillium italicum using Surface-Enhanced Raman Spectroscopy (SERS). Sci. Rep. 9:490. doi: 10.1038/s41598-018-36989-7

Jerkovic, I., Gaso-Sokac, D., Pavlovic, H., Marijanovic, Z., Gugic, M., Petrovic, I., et al. (2012). Volatile organic compounds from Centaurium erythraea Rafn (Croatia) and the antimicrobial potential of its essential oil. Molecules 17, 2058-2072. doi: 10.3390/molecules17022058

Ji, P., Csinos, A. S., Hickman, L. L., and Hargett, U. (2014). Efficacy and Application Methods of Oxathiapiprolin for Management of Black Shank on Tobacco. Plant Dis. 98, 1551-1554. doi: 10.1094/PDIS-02-14-0172-RE

Jian, W., He, D., Xi, P., and Li, X. (2015). Synthesis and biological evaluation of novel fluorine-containing stilbene derivatives as fungicidal agents against phytopathogenic fungi. J. Agric. Food Chem. 63, 9963-9969. doi: 10.1021/acs. jafc.5b04367

Jiang, R. H. Y., and Tyler, B. M. (2012). Mechanisms and Evolution of Virulence in Oomycetes. Annu. Rev. Phytopathol. 50, 295-318.

Kamoun, S., Furzer, O., Jones, J. D., Judelson, H. S., Ali, G. S., Dalio, R. J., et al. (2015). The Top 10 oomycete pathogens in molecular plant pathology. Mol. Plant Pathol. 16, 413-434. doi: 10.1111/mpp.12190

Kapsi, M., Tsoutsi, C., Paschalidou, A., and Albanis, T. (2019). Environmental monitoring and risk assessment of pesticide residues in surface waters of the Louros River (N.W. Greece). Sci. Total Environ. 650, 2188-2198. doi: 10.1016/j. scitotenv.2018.09.185

Krajaejun, T., Lowhnoo, T., Yingyong, W., Rujirawat, T., Fucharoen, S., and Strobel, G. A. (2012). In vitro antimicrobial activity of volatile organic compounds from Muscodor crispans against the pathogenic oomycete Pythium insidiosum. Southeast Asian J. Trop. Med. Public Health 43, 1474-1483.

Lee, K. K., Kubo, K., Abdelaziz, J. A., Cunningham, I., de Silva Dantas, A., Chen, X., et al. (2018). Yeast species-specific, differential inhibition of beta-1,3-glucan synthesis by poacic acid and caspofungin. Cell Surf. 3, 12-25. doi: 10.1016/j. tcsw.2018.09.001

Li, Y., Harris-Shultz, K., Wang, H., Wadl, P. A., and Ji, P. (2017). Population Structure and Genetic Diversity of Phytophthora nicotianae from Tobacco in Georgia. Plant Dis. 101, 1113-1118. doi: 10.1094/PDIS-01-170142-RE

Liang, C., Gao, W., Ge, T., Tan, X., Wang, J., Liu, H., et al. (2021). Lauric Acid Is a Potent Biological Control Agent That Damages the Cell Membrane of Phytophthora sojae. Front. Microbiol. 12:666761. doi: 10.3389/fmicb.2021. 666761

Liao, M., Ren, X., Gao, Q., Liu, N., Tang, F., Wang, G., et al. (2021). Antifungal activity of moso bamboo (Phyllostachys pubescens) leaf extract and its development into a botanical fungicide to control pepper phytophthora blight. Sci. Rep. 11:4146. doi: 10.1038/s41598-021-83598-y

Lorsbach, B. A., Sparks, T. C., Cicchillo, R. M., Garizi, N. V., Hahn, D. R., and Meyer, K. G. (2019). Natural products: a strategic lead generation approach in crop protection discovery. Pest Manag. Sci. 75, 2301-2309. doi: 10.1002/ps.5350
Mackie, K. A., Muller, T., Zikeli, S., and Kandeler, E. (2013). Long-term copper application in an organic vineyard modifies spatial distribution of soil microorganisms. Soil Biol. Biochem. 65, 245-253. doi: 10.1016/j.soilbio.2013.06.003

Matson, M. E., Small, I. M., Fry, W. E., and Judelson, H. S. (2015). Metalaxyl Resistance in Phytophthora infestans: assessing Role of RPA190 Gene and Diversity Within Clonal Lineages. Phytopathology 105, 1594-1600. doi: 10.1094/ PHYTO-05-15-0129-R

Matsui, K., and Koeduka, T. (2016). Green Leaf Volatiles in Plant Signaling and Response. Subcell. Biochem. 86, 427-443. doi: 10.1007/978-3-319-25979-6_17

Mellon, J. E., Dowd, M. K., Beltz, S. B., and Moore, G. G. (2014). Growth inhibitory effects of gossypol and related compounds on fungal cotton root pathogens. Lett. Appl. Microbiol. 59, 161-168. doi: 10.1111/lam.12262

Miao, J., Dong, X., Lin, D., Wang, Q., Liu, P., Chen, F., et al. (2016). Activity of the novel fungicide oxathiapiprolin against plant-pathogenic oomycetes. Pest Manag. Sci. 72, 1572-1577. doi: 10.1002/ps.4189

Naz, R., Nosheen, A., Yasmin, H., Bano, A., and Keyani, R. (2018). Botanicalchemical formulations enhanced yield and protection against Bipolaris sorokiniana in wheat by inducing the expression of pathogenesis-related proteins. PLoS One 13:e0196194. doi: 10.1371/journal.pone.0196194

Nino, J., Mosquera, O. M., and Correa, Y. M. (2012). Antibacterial and antifungal activities of crude plant extracts from Colombian biodiversity. Rev. Biol. Trop. 60, 1535-1542. doi: 10.15517/rbt.v60i4.2071

Pang, Z., Chen, L., Mu, W., Liu, L., and Liu, X. (2016). Insights into the adaptive response of the plant-pathogenic oomycete Phytophthora capsici to the fungicide flumorph. Sci. Rep. 6:24103. doi: 10.1038/srep24103

Pemberton, I. J., Smith, G. R., Philley, G. L., Rouquette, F. M. Jr., and Yuen, G. Y. (1998). First Report of Pythium ultimum, P. irregulare, Rhizoctonia solani AG4, and Fusarium proliferatum from Arrowleaf Clover (Trifolium vesiculosum): a Disease Complex. Plant Dis. 82:128. doi: 10.1094/PDIS.1998.82.1.128B

Piotrowski, J. S., Okada, H., Lu, F., Li, S. C., Hinchman, L., Ranjan, A., et al. (2015). Plant-derived antifungal agent poacic acid targets beta-1,3-glucan. Proc. Natl. Acad. Sci. U. S. A. 112, E1490-E1497. doi: 10.1073/pnas.1410400112

Randall, E., Young, V., Sierotzki, H., Scalliet, G., Birch, P. R., Cooke, D. E., et al. (2014). Sequence diversity in the large subunit of RNA polymerase I contributes to Mefenoxam insensitivity in Phytophthora infestans. Mol. Plant Pathol. 15, 664-676. doi: 10.1111/mpp.12124

Rekanovic, E., Potocnik, I., Milijasevic-Marcic, S., Stepanovic, M., Todorovic, B., and Mihajlovic, M. (2012). Toxicity of metalaxyl, azoxystrobin, dimethomorph, cymoxanil, zoxamide and mancozeb to Phytophthora infestans isolates from Serbia. J. Environ. Sci. Health B 47, 403-409. doi: 10.1080/03601234.2012. 657043

Ricciardi, V., Marciano, D., Sargolzaei, M., Maddalena, G., Maghradze, D., Tirelli, A., et al. (2021). From plant resistance response to the discovery of antimicrobial compounds: the role of volatile organic compounds (VOCs) in grapevine downy mildew infection. Plant Physiol. Biochem. 160, 294-305. doi: 10.1016/j.plaphy.2021.01.035

Scala, A., Allmann, S., Mirabella, R., Haring, M. A., and Schuurink, R. C. (2013). Green leaf volatiles: a plant's multifunctional weapon against herbivores and pathogens. Int. J. Mol. Sci. 14, 17781-17811. doi: 10.3390/ijms140917781

Schnee, S., Queiroz, E. F., Voinesco, F., Marcourt, L., Dubuis, P. H., Wolfender, J. L., et al. (2013). Vitis vinifera canes, a new source of antifungal compounds against Plasmopara viticola, Erysiphe necator, and Botrytis cinerea. J. Agric. Food Chem. 61, 5459-5467. doi: $10.1021 /$ jf4010252

Shuping, D. S. S., and Eloff, J. N. (2017). The Use Of Plants To Protect Plants And Food against Fungal Pathogens: a Review. Afr. J. Tradit. Complement. Altern. Med. 14, 120-127. doi: 10.21010/ajtcam.v14i4.14

Siegenthaler, T. B., and Hansen, Z. (2021). Sensitivity of Phytophthora capsici from Tennessee to mefenoxam, fluopicolide, oxathiapiprolin, dimethomorph, mandipropamid, and cyazofamid. Plant Dis. [Epub Online ahead of print]. doi: 10.1094/PDIS-08-20-1805-RE

Suthiwong, J., Sriphana, U., Thongsri, Y., Promsuwan, P., Prariyachatigul, C., and Yenjai, C. (2014). Coumarinoids from the fruits of Micromelum falcatum. Fitoterapia 94, 134-141. doi: 10.1016/j.fitote.2014.02.004

Tan, X., Hu, Y., Jia, Y., Hou, X., Xu, Q., Han, C., et al. (2020). A Conserved Glycoside Hydrolase Family 7 Cellobiohydrolase PsGH7a of Phytophthora sojae Is Required for Full Virulence on Soybean. Front. Microbiol. 11:1285. doi: 10. 3389/fmicb.2020.01285 
Tanaka, T., Ikeda, A., Shiojiri, K., Ozawa, R., Shiki, K., Nagai-Kunihiro, N., et al. (2018). Identification of a Hexenal Reductase That Modulates the Composition of Green Leaf Volatiles. Plant Physiol. 178, 552-564. doi: 10.1104/pp.18.00632

Thines, M., and Kamoun, S. (2010). Oomycete-plant coevolution: recent advances and future prospects. Curr. Opin. Plant Biol. 13, 427-433. doi: 10.1016/j.pbi. 2010.04.001

Thuerig, B., James, E. E., Scharer, H. J., Langat, M. K., Mulholland, D. A., Treutwein, J., et al. (2018). Reducing copper use in the environment: the use of larixol and larixyl acetate to treat downy mildew caused by Plasmopara viticola in viticulture. Pest Manag. Sci. 74, 477-488. doi: 10.1002/ps.4733

Tschoeke, P. H., Oliveira, E. E., Dalcin, M. S., Silveira-Tschoeke, M., Sarmento, R. A., and Santos, G. R. (2019). Botanical and synthetic pesticides alter the flower visitation rates of pollinator bees in Neotropical melon fields. Environ. Pollut. 251, 591-599. doi: 10.1016/j.envpol.2019.04.133

$\mathrm{Tu}, \mathrm{Y}$. (2011). The discovery of artemisinin (qinghaosu) and gifts from Chinese medicine. Nat. Med. 17, 1217-1220. doi: 10.1038/nm.2471

Tyler, B., Tripathy, S., Zhang, X., Dehal, P., Jiang, R., Aerts, A., et al. (2006). Phytophthora genome sequences uncover evolutionary origins and mechanisms of pathogenesis. Science 313, 1261-1266.

Tyler, B. M. (2007). Phytophthora sojae: root rot pathogen of soybean and model oomycete. Mol. Plant Pathol. 8, 1-8. doi: 10.1111/j.1364-3703.2006.00373.x

Tyler, B. M., Wu, M., Wang, J., Cheung, W., and Morris, P. F. (1996). Chemotactic Preferences and Strain Variation in the Response of Phytophthora sojae Zoospores to Host Isoflavones. Appl. Environ. Microbiol. 62, 2811-2817.

Ulloa-Benitez, A., Medina-Romero, Y. M., Sanchez-Fernandez, R. E., LappeOliveras, P., Roque-Flores, G., Duarte Lisci, G., et al. (2016). Phytotoxic and antimicrobial activity of volatile and semi-volatile organic compounds from the endophyte Hypoxylon anthochroum strain Blaci isolated from Bursera lancifolia (Burseraceae). J. Appl. Microbiol. 121, 380-400. doi: 10.1111/jam. 13174

Wang, B., Li, P., Xu, S., Liu, L., Xu, Y., Feng, X., et al. (2021). Inhibitory Effects of the Natural Product Esculetin on Phytophthora capsici and Its Possible Mechanism. Plant Dis. [Epub Online ahead of print]. doi: 10.1094/PDIS-09-20-2054-RE

Wang, Y., Sun, Y., Zhang, Y., Zhang, X., and Feng, J. (2016). Antifungal Activity and Biochemical Response of Cuminic Acid against Phytophthora capsici Leonian. Molecules 21:756. doi: 10.3390/molecules21060756

Wen, L., Lee-Marzano, S., Ortiz-Ribbing, L. M., Gruver, J., Hartman, G. L., and Eastburn, D. M. (2017). Suppression of Soilborne Diseases of Soybean With Cover Crops. Plant Dis. 101, 1918-1928. doi: 10.1094/PDIS-07-16-1067-RE
Wightwick, A. M., Salzman, S. A., Reichman, S. M., Allinson, G., and Menzies, N. W. (2013). Effects of copper fungicide residues on the microbial function of vineyard soils. Environ. Sci. Pollut. Res. Int. 20, 1574-1585. doi: 10.1007/s11356012-1114-7

Xing, M., Zheng, L., Deng, Y., Xu, D., Xi, P., Li, M., et al. (2018). Antifungal Activity of Natural Volatile Organic Compounds against Litchi Downy Blight Pathogen Peronophythora litchii. Molecules 23:358. doi: 10.3390/molecules23 020358

Xu, Y., Tong, Z., Zhang, X., Zhang, X., Luo, Z., Shao, W., et al. (2021). Plant volatile organic compound (E)-2-hexenal facilitates Botrytis cinerea infection of fruits by inducing sulfate assimilation. New Phytol. 231, 432-446. doi: 10.1111/nph. 17378

Yoon, M. Y., Cha, B., and Kim, J. C. (2013). Recent trends in studies on botanical fungicides in agriculture. Plant Pathol. J. 29, 1-9. doi: 10.5423/PPJ.RW.05.2012. 0072

Yutin, N., Makarova, K. S., Mekhedov, S. L., Wolf, Y. I., and Koonin, E. V. (2008). The deep archaeal roots of eukaryotes. Mol. Biol. Evol. 25, 1619-1630. doi: $10.1093 / \mathrm{molbev} / \mathrm{msn} 108$

Conflict of Interest: YW was employed by company Shimadzu (China) Co., Ltd.

The remaining authors declare that the research was conducted in the absence of any commercial or financial relationships that could be construed as a potential conflict of interest.

Publisher's Note: All claims expressed in this article are solely those of the authors and do not necessarily represent those of their affiliated organizations, or those of the publisher, the editors and the reviewers. Any product that may be evaluated in this article, or claim that may be made by its manufacturer, is not guaranteed or endorsed by the publisher.

Copyright (c) 2021 Ge, Gao, Liang, Han, Wang, Xu and Wang. This is an openaccess article distributed under the terms of the Creative Commons Attribution License (CC BY). The use, distribution or reproduction in other forums is permitted, provided the original author(s) and the copyright owner(s) are credited and that the original publication in this journal is cited, in accordance with accepted academic practice. No use, distribution or reproduction is permitted which does not comply with these terms. 